\title{
EL ORDEN INTERNACIONAL DESPUÉS DE LA PANDEMIA DEL COVID-19: ACELERACIÓN DE LA HISTORIA Y AGUDIZACIÓN DE LAS DESIGUALDADES
}

THE INTERNATIONAL ORDER AFTER THE COVID-19 PANDEMIC: HISTORY ACCELERATION AND DEEPENING INEQUALITIES

Héctor Ernesto Herrera Capetillo hherrera@politicas.unam.mx 
Para citar este artículo:

Herrera Capetillo, H. E. (2020). El orden internacional después de la pandemia del COVID-19 aceleración de la historia y agudización de las desigualdades. ESPACIO I+D, INNOVACIÓN MÁS DESARROLLO, 9(25). https://doi.org/10.31644/IMASD.25.2020.a03

\section{RESUMEN}

La irrupción de la pandemia de la COVID-1 9 provocará cambios en el orden internacional, sin embargo, contrario a quienes sostienen que dará origen a un escenario radicalmente distinto, lo que hemos visto es la aceleración de procesos que venían ocurriendo tiempo atrás como el declive de la hegemonía estadounidense, un mayor protagonismo de China, la emergencia de Estados más autoritarios, fracturas al interior de las organizaciones internacionales, pero también el surgimiento de ciertas iniciativas de cooperación, la agudización de las desigualdades producto de la pandemia y la crisis económica, así como un renovado estallido social que pone en cuestionamiento las exclusiones sistemáticas previas.

\section{Palabras Clave}

COVID-19; orden internacional; conflicto y cooperación internacional. 


\section{- Abstract-}

The emergence of the COVID-I 9 pandemic will cause changes in the international order, however, contrary to those who argue that it will give rise to a radically different scenario, what we have seen is the acceleration of processes that had been occurring for some time behind as the decline of US hegemony, a greater role of China, the emergence of more authoritarian states, fractures within international organizations, but also the emergence of certain cooperation initiatives, the exacerbation of inequalities resulting from the pandemic and the economic crisis, as well as a renewed social outbreak that calls into question the previous systematic exclusions.

\section{Keywords}

COVID- I9; international order; conflict and international cooperation. 
as pandemias y la política internacional tienen una larga historia. Una de las obras consideradas precursoras de la disciplina de Relaciones Internacionales, y en particular de la corriente del realismo político, es la Historia de la Guerra del Peloponeso escrita por Tucídides en el siglo V a.C. En su libro segundo, el historiador narra las consecuencias de la peste de Atenas que asoló a esta ciudad-estado en el año 430 a.C.y que cobró la vida de aproximadamente un tercio de la población total (Hays, 2005; Dagnino, $20 \mathrm{II}$ ), incluidas entre ellas la del político y militar ateniense Pericles, cuya muerte trazó posiblemente un curso distinto de la guerra contra Esparta, en la cual la Liga de Delos, comandada por Atenas, fue derrotada.

A la extensa lista de pandemias que tuvieron repercusiones considerables para el orden político de su época, debemos mencionar además de la peste de Atenas, al menos, otras cuatro importantes: I) la plaga de Justiniano, que devastó al Imperio Bizantino en el año 54I, costó la vida de cuarenta por ciento de la población de la capital, afectó su economía y la expansión del imperio que lo mantenía enfrentado con Persia por la hegemonía regional (Pirazzini, 20l8; Martínez, 2019); 2) la peste negra, que se tradujo en la perdida de aproximadamente treinta por cierto de la población europea en el siglo XIV, alteró los balances regionales, trasladando el liderazgo económico de las ciudades del Mediterráneo, como Florencia, a las del noroeste de Europa, marcó el declive del feudalismo y el ascenso del capitalismo (Pamuk, 2007; Chaturvedi, 2020); 3) la pandemia de viruela del siglo XVI en América que se estima mató al noventa por ciento de la población aborigen y con ello facilitó la conquista del continente a manos de las potencias europeas (Kreibohm, 2020); y 4) la gripe española de 1918 que no solo representó la perdida de cerca de cincuenta millones de personas, sino que también repercutió en la salud de los ejércitos y, por lo tanto, en el curso y conclusión de la Primera Guerra Mundial (Hays, 2005).

Las pandemias han sido clave en la formación de grandes procesos históricos. En ese sentido, la ya nombrada primera plaga pandémica (peste de Justiniano, 54I-762) fue trascendental en el fin de la Edad Antigua (Little, 2006), y la segunda de este tipo (peste negra, 1347) en el desenlace de la Edad Media. El objetivo de controlar esta última pandemia llevó, de acuerdo con Harrison, a la formación del Estado moderno (Bollyky, 2020) y con ello, a la regulación comercial, entre cuyas medidas restrictivas encontramos las cuarentenas y los embargos sanitarios (Harrison, 2012). Otros autores como Watts (1999) consideran que las plagas han sido herramientas imprescindibles para el avance del imperialismo.

Desde luego, no todas las pestes han suscitado por sí mismas cambios importantes en el orden político, menos aún lo han hecho de forma inmediata, pues suelen ser enfermedades que duran por años o con rebrotes cíclicos a lo largo de siglos; y tampoco resulta preciso afirmar que han sido el 
único ni el más importante factor responsable de tales transformaciones, sin embargo, y es la primera premisa de la cual parte el presente artículo, podemos argumentar que han contribuido a acelerar procesos que ya estaban en curso cuando éstas emergieron. Atenas se encontraba ya en declive antes de la peste del siglo V a.C., el Imperio Bizantino experimentó disturbios internos como los de Niká previos a la plaga de Justiniano y la gran guerra europea de principios del siglo $X X$ fue reflejo de los cambios que vivía el orden regional antes de la aparición de la gripe española. Más que crear nuevos escenarios, las consecuencias económicas, demográficas y políticas de las pandemias, aceleran otros cambios más estructurales que ya venían ocurriendo y que, finalmente, repercuten en la modificación del orden internacional.

Una segunda premisa esbozada por este texto es que el escenario que emerja después de la pandemia será probablemente más parecido al orden de la primera postguerra que al de la segunda. A diferencia de la Segunda Guerra Mundial, cuya conclusión marcó el final de la dominación europea y el ascenso indiscutible de dos nuevas superpotencias, los Estados Unidos y la Unión Soviética, la Primera Guerra Mundial no aniquiló a las antiguas potencias lo que, sumado a la reticencia estadounidense de asumir un papel más protagónico, generó un vacío de poder. En ese sentido, el orden internacional post pandemia COVID-I 9 difícilmente se traducirá en el colapso súbito de la hegemonía construida por los Estados Unidos, pero tampoco en el ascenso inmediato del liderazgo chino.

Por último, contrario a las visiones que sugieren que después de las grandes crisis surgen momentos de cooperación entre los Estados y las que, desde el extremo opuesto, consideran que son causantes de una mayor tensión y desconfianza internacionales, nuestra tercera premisa sostiene que resulta más probable la emergencia de un escenario pragmático, que combine nuevos mecanismos de cooperación, por ejemplo, en materia sanitaria, pero también mayores fricciones en torno a la legitimidad y funcionamiento de las organizaciones internacionales, como lo hemos visto con la Organización Mundial de la Salud (OMS), producto de una mayor tensión entre Estados Unidos y China.

Con el objetivo de estudiar las consecuencias de la actual pandemia al orden internacional, el presente texto abordará, en primer lugar, la definición de orden en el plano global y el papel que desempeña la hegemonía en él; en segundo, ahondará en los procesos históricos que, consideramos, se han acelerado a raíz de la actual crisis, entre ellos la agudización de las desigualdades y, finalmente, concluirá con el resumen de los principales hallazgos de nuestro trabajo. 


\section{ORDEN INTERNACIONAL Y HEGEMONÍA}

En el lenguaje cotidiano el orden describe formas de comportamiento regulares, estables y predecibles, que sugieren continuidad, en contraste, el desorden alude al caos y la conducta violenta y, por lo tanto, a un escenario inestable y de constantes cambios (Heywood, 20I5). En el plano mundial, como apuntan Griffiths y O'Callaghan (2002), el orden hace referencia a patrones estables de relaciones entre actores internacionales que mantienen un conjunto de objetivos o propósitos comunes. En condiciones de anarquía, es decir, en contextos como el internacional donde no existe una autoridad por encima de los Estados, los realistas consideran que el balance de poder y las alianzas interestatales resultan aspectos clave para la manutención del orden, mientras que los liberales ven esa función en las instituciones internacionales y en las normas de conducta que éstas generan.

Contrario a las visiones que lo homologan con armonía, paz o justicia, el orden puede ser concebido, de la misma forma en que Agnew y Corbridge (1995) hacen, como una mezcla de cohesión y conflicto entre actores que se organizan bajo un sistema de gobernanza, es decir, de reglas de operación, principios de interacción y supuestos ampliamente compartidos sobre comercio, fuerza y diplomacia. Además de la existencia de regímenes en torno a temas particulares, el orden internacional también requiere de suposiciones intersubjetivas compartidas por los actores principales. El desorden, en consecuencia, se presenta cuando esa gobernanza colapsa y el cambio que socavó el antiguo orden no ha producido uno nuevo (Agnew y Corbridge, 1995).

Tanto los realistas clásicos como los neorrealistas reducen la estructura del orden mundial al equilibro de poder que surge de la configuración de la fuerza material de los Estados. Desde la teoría de la estabilidad hegemónica, como argumentan Krasner y Webb (1989), la estabilidad del orden es más fuerte cuando existe un Estado dominante único como la Pax Britannica del siglo XIX y la Pax Americana del siglo XX sugieren.

Desde un enfoque gramsciano, y como crítica a la visión realista, la hegemonía que mantiene el orden internacional está basada tanto en la configuración del poder material como en un conjunto de instituciones que lo administran, en tal lógica, el poder del Estado ya no aparece como un factor explicativo, en el sentido en que los realistas argumentan, sino como parte de aquello que también necesitamos explicar, pues las relaciones internacionales suceden o son consecuencia de las relaciones sociales al interior de los Estados (Cox, 20I4). La dominación de un actor poderoso, por lo tanto, no es condición suficiente para una situación de hegemonía, pues como ilustra el escenario de la primera postguerra, el Estado con más fuerza no siempre asume un papel protagónico en el sistema internacional, $y$ las reglas del esquema preexistente podrían mantenerse por la aprobación 
del resto de los Estados, y casi por inercia, aunque no haya un poder material reforzándolo.

El orden internacional basado en la hegemonía de un Estado se construye, desde la apreciación gramsciana, sobre una combinación de coerción y consenso. Así, la Pax Britannica asentó su dominio no solo en el poder naval británico, sino también en el conjunto de normas de la economía liberal, como el libre comercio y el patrón oro, que eran reguladas por el Estado dominante, pero seguidas por el resto de la sociedad internacional (Cox, 20I4). De la misma forma, la Pax Americana, inaugurada después de la Segunda Guerra Mundial, basó su proyecto tanto en la fuerza económica y militar estadounidense como en las organizaciones internacionales que surgieron de los Acuerdos de Bretton Woods y el sistema de Naciones Unidas. Como señala Nye (1990), si un Estado puede legitimar su poder ante los ojos de los demás y crear instituciones que incentiven a que otros actores canalicen o limiten sus actividades de la forma en que el dominante prefiera, encontrará menos resistencia a sus deseos y una menor necesidad de desplegar diversos y costosos ejercicios de poder coercitivo en situaciones de negociación.

Para autores como Agnew y Corbridge (1995), en los últimos dos siglos podemos definir tres órdenes geopolíticos: I) El Concierto de Europa, liderado por el Imperio Británico, que va de la derrota napoleónica en I8I 5 al ascenso alemán en 1875; 2) el orden geopolítico de la Rivalidad Interimperial de 1875 al final de la Segunda Guerra Mundial en 1945, caracterizado por el enfrentamiento entre los Imperios Británico y Alemán que se tradujo en dos grandes confrontaciones mundiales; y 3) el orden de la Guerra Fría, que comenzó en 1945 y terminó con los cambios políticos en Europa del Este en 1990. Por su parte, Cox (2000) divide el mismo periodo en cuatro momentos, dos hegemónicos y dos no-hegemónicos. En el primer periodo (1845-1875), encontramos como centro de la economía mundial al Imperio Británico; en el segundo (I875-1945), las características del orden previo fueron revertidas y el balance de poder en Europa desestabilizado; en el tercero (1945-1965), los Estados Unidos fundaron un nuevo orden hegemónico similar al británico; y en el cuarto (1965-al presente), el ordenamiento previo comenzó a experimentar problemas.

Si bien estos autores difieren en la periodización del orden internacional, en ambos casos concuerdan en que nos encontramos, ya sea desde 1965 como sugiere Cox o desde 1990 como Agnew y Corbridge, en un periodo de cambios que no ha terminado de dar forma a un nuevo orden, en palabras de Gramsci, lo viejo no ha muerto y lo nuevo no ha podido nacer aún. En ese contexto de crisis o de transición intersistémica, la pandemia del COVID- 19 ha emergido acelerando tendencias previas, que podíamos observar ya desde hace unas cuantas décadas, y ha agudizado aún más la desigualdad. 


\section{ACELERACIÓN DE LA HISTORIA Y AGUDIZACIÓN DE LAS DESIGUALDADES}

En su Fenomenología del Espíritu (1807), Georg Hegel consideraba que la historia había llegado a su fin con la victoria napoleónica sobre Prusia. en la famosa Batalla de Jena de 1806. Con ello, señalaba el filósofo alemán, habían triunfado los ideales de la Revolución Francesa y la universalización del Estado. basado en los principios de libertad e igualdad. En analogía a esa idea, Francis Fukuyama, experto en política exterior soviética, anunció nuevamente el fin de la historia en una conferencia en la Universidad de Chicago en febrero de 1989. En un texto, publicado por la revista The National Interest ese mismo verano, Fukuyama (1989) argumentaba que, con la disolución de la Unión Soviética y el final del socialismo, la última alternativa ideológica al liberalismo había desaparecido, por lo cual, el mundo se dirigía finalmente hacia una sociedad racional victoriosa, patente en la expansión de un orden liberal basado en la democracia representativa y el libre mercado.

Ese mismo año, la declaración del fin de la Guerra Fría hecha por George Kennan, famoso arquitecto de la política de contención del socialismo; el anuncio de la "Doctrina Sinatra" por medio de la cual el Kremlin renunciaba al intervencionismo soviético en los países que componían el Pacto de Varsovia; la destrucción del Muro de Berlín; la posterior reunificación alemana y, más adelante, la disolución de la Unión Soviética, favorecieron la tesis de Fukuyama. Sin embargo, hechos como la Matanza de Tiananmén en junio de 1989, las Guerras Yugoslavas y el Genocidio en Ruanda en la década de 1990, la reemergencia de los nacionalismos y fundamentalismos religiosos, el intervencionismo estadounidense en Medio Oriente como parte de su campaña antiterrorista y, más recientemente, el ascenso del populismo de derecha en países tan distintos como Estados Unidos, Francia, Alemania, Hungría, Brasil o India, han puesto en evidencia no solo los límites de esta afirmación tan idealista, sino también un proceso más profundo de crisis.

La actual pandemia, como señala Bringel (2020), ha llegado en un momento histórico de agotamiento de recursos naturales, de emergencia ambiental, retrocesos democráticos, y desconfianza y rechazo a los sistemas políticos, al que debemos agregar una progresiva individualización y fragmentación social, así como el crecimiento de las desigualdades no solo entre países, sino también al interior de éstos. En ese contexto, el mundo post pandemia difícilmente será muy diferente al que le precedió, pues como apunta Hass (2020), la COVID-19 no cambiará tanto la dirección de la historia mundial como la acelerará, profundizando más aún la crisis del orden internacional y las brechas de desigualdad. Por lo tanto, y con base en lo observado durante los meses que lleva la pandemia en curso, 
consideramos que la aceleración de los procesos históricos nos coloca ante las siguientes cuatro tendencias:

a. Declive de la hegemonía estadounidense y ascenso del liderazgo chino: Desde la década de 1970 el orden geopolítico de la Guerra Fría, como apuntan Agnew y Corbridge (1995) se ha desmoronado lentamente con el colapso del sistema monetario internacional surgido de los Acuerdos Bretton Woods y con la crisis de los precios del petróleo. El breve momento unipolar que surgió tras la disolución de la Unión Soviética en la década de 1990 fue mostrando cada vez más sus limitaciones, hasta que el sobre estiramiento imperial, con las intervenciones estadounidenses en Afganistán e Irak a principios del siglo XXI, se tradujo en la fractura del consenso de la posguerra, al generar tensiones con aliados tradicionales como Francia $y$ Alemania. Si bien Estados Unidos se mantiene todavía como el mayor poder económico y militar del planeta, el crecimiento acelerado de China en las últimas décadas ha provocado fricciones más constantes entre estos dos países, al punto que para algunos analistas como Allison (20l7), corren el riesgo de caer en la conocida "Trampa de Tucídides", fenómeno que describe la guerra casi inevitable entre dos potencias -una en declive y la otra en ascenso- que rivalizan por la hegemonía mundial. De los dieciséis escenarios de confrontación que se han presentado entre el siglo XV y la actualidad, solo cuatro de ellos no han concluido en una guerra. La rivalidad entre Estados Unidos y China se ha vuelto cada vez más patente entre acusaciones mutuas de espionaje, robo de propiedad intelectual, sanciones arancelarias y la creciente carrera tecnológica en áreas como el $5 \mathrm{G}$ de la telefonía móvil o en informática, pues mientras en 2009, China tenía 21 de los 500 superordenadores del mundo y Estados Unidos 277, en la actualidad, el país asiático posee 227 frente a los II 8 de su competidor americano (Zibechi, 2020a).

Desde el principio de la pandemia, como señala Loyer y Giblin (2020), Estados Unidos abandonó su posición de líder mundial, cerró sus fronteras aéreas y terrestres, suspendió toda migración y no otorgó ayuda ni siquiera a sus aliados europeos, por el contrario, fue acusado por Francia y Alemania de confiscar material sanitario dirigido a ellos (Drury, 04 de abril de 2020), invocó la Ley de Producción de Defensa promulgada durante la Guerra de Corea en 1950 para obligar a la empresa 3M a producir mascarillas y dejar de exportarlas a Canadá y América Latina (BBC News, 03 de abril de 2020), quiso comprar la exclusividad de una vacuna contra el COVID-I 9 desarrollada por Alemania (DW, I6 de marzo de 2020) y anunció su salida de la Organización Mundial de la Salud (BBC News, 07 de julio de 2020). En contraste, como parte de la llamada diplomacia de las mascarillas, China envió epidemiólogos y material sanitaria a países de Europa, América Latina 
y África, y desplegó una amplia red de infraestructura bajo el modelo de la "nueva ruta de la seda" (Loyer y Giblin, 2020). Sin embargo, aunque creciente, el liderazgo chino depende aún de diversos factores en el corto, mediano y largo plazo, como la recuperación económica mundial, el control y la estabilidad de su región central, pues como señala Tunsjø (2018), China tiene conflictos territoriales y marítimos con sus vecinos asiáticos. Sumado a lo anterior, el país asiático deberá desarrollar la vacuna contra el COVID-19 antes que Estados Unidos, para obtener puntos en la carrera tecnológica y propagandística, así como invertir en su imagen, pues la campaña contra la actuación del gobierno chino durante la pandemia generó desconfianza en diversos actores de la sociedad internacional.

b. Entre el unilateralismo estatal y la cooperación multilateral: La pandemia del COVID- 19 irrumpió en el marco del $75^{\circ}$ aniversario de los arreglos de la segunda postguerra que dieron origen a la Organización de las Naciones Unidas. En ese contexto, su actuación, así como la de otras organizaciones internacionales y regionales, ha enfrentado duras críticas. El llamado de alto al fuego en los conflictos mundiales hecho por la Secretaría General en marzo de este año, y que alcanzó el respaldo de 170 Estados (Noticias ONU, 24 de junio de 2020), nunca se tradujo en acciones concretas (La Jornada, 27 de mayo de 2020) y una resolución en el Consejo de Seguridad en el mismo sentido fue vetado por Estados Unidos debido a la insistencia china de mencionar en el documento a la Organización Mundial de la Salud (Atwood, 09 de mayo de 2020).

En el marco de la pandemia, Trump no solo cuestionó el trabajo de la OMS en repetidas ocasiones, acusándola de ser cercana a China, sino que también amenazó con retirar las contribuciones estadounidenses, lo que finalmente llevó a su salida. En el mismo sentido, el presidente brasileño Jair Bolsonaro desacreditó las medidas sanitarias recomendadas y las estadísticas proporcionadas por la OMS (Milani, 2020), y tan solo dos días después de que la COVID- I 9 fuera decretada como pandemia, el ministro de salud de la India señaló que no se trataba de una emergencia sanitaria (Roy, 2020).

Las críticas a las organizaciones internacionales no son nuevas, mientras en la narrativa de la izquierda son asociadas al proyecto hegemónico estadounidense, en los discursos de la derecha populista aparecen como promotoras de la inmigración y de políticas que limitan el margen de acción de los Estados soberanos, más aún, en la retórica de Trump, se presentan como ineficientes, costosas y cooptadas por rivales de Estados Unidos como China. En ese sentido, no sorprende que en la actual crisis la primera respuesta de los gobiernos haya sido el unilateralismo y el aislamiento. Incluso en la región con un proyecto comunitario más sólido, la Unión Europea, las medidas nacionales divergentes se impusieron ante la ausencia 
de directivas conjuntas y, como señala Morillas (2020), las compensaciones a empresas y trabajadores se diseñaron con lógica nacional, mientras que los cierres de las fronteras restringieron las libertades de movimiento asociadas al Acuerdo de Schengen. Una encuesta realizada a finales de abril a ciudadanos de los países de la Unión Europea apuntaba que 57\% estaba insatisfecho con la solidaridad mostrada por los Estados miembro -un malestar particularmente fuerte entre los países más afectados como Italia, España y Grecia-, en contraste, $54 \%$ de los ciudadanos apoyaban a su gobierno nacional (Zalc y Maillard, 2020). El proyecto comunitario, como subraya Bringel (2020), fracasó en presentarse hacia el exterior como una alternativa democrática y eficiente al modelo autoritario chino, pero también a la respuesta fallida de los Estados Unidos. Hacia el interior, por otra parte, desaprovechó, como lo hizo en la crisis económica de 2008 y la crisis de refugiados de 20 I5, la oportunidad de fortalecer la solidaridad regional y en ofrecer una respuesta más rápida y precisa a la pandemia (Romero, 2020).

A pesar del unilateralismo anteriormente esbozado, también se han dado muestras de una renovada cooperación internacional. A finales de julio, el Consejo Europeo aprobó un fondo histórico por 750 mil millones de euros financiado por la emisión de deuda conjunta, de los cuales 390 mil millones serán subvenciones y ayudas directas y 360 mil millones préstamos. Aunque finalmente se logró el acuerdo impulsado por Francia y Alemania, la negociación puso en evidencia las fracturas internas y las diferencias regionales entre los países del Norte y el Sur europeo, pues la "Nueva Liga Hanseática” integrada por Países Bajos, Suecia, Dinamarca, Austria y Finlandia, lograron poner ciertos frenos de emergencia a los fondos para exigir el seguimiento de un programa de otro país, lo que podría retrasar el desembolso de recursos y pidieron, adicionalmente, más condiciones para que los países del Sur obtuvieran los préstamos (Gómez, 22 de julio de 2020).

Además de los apoyos internos, la Unión Europea destinó recursos para proveer suministros médicos y reforzar los sistemas de salud en países de los Balcanes, Europa del Este y el Sahel en África; Japón apoyó a los países de la Asociación de Naciones del Sureste Asiático (ASEAN), y China, a diferencia de Europa y Japón, no solo ofreció ayuda a los países de menor desarrollo, sino que también incluyó en su lista a otros como Alemania e Italia. Más allá de los actores gubernamentales, empresas como Huawei donaron mascarillas, Alibaba pruebas de detección de COVID-I 9 y la fundación Bill y Melinda Gates aumentaron sus donaciones a la OMS para contrarrestar la amenaza estadounidense de retirar el financiamiento a la organización (Zalazar, 2020).

Un tema, sin embargo, que parece romper con las tendencias previas observadas antes de la pandemia, es la prioridad que comenzará a tener la 
salud en la agenda internacional. Como señala Astié-Burgos (20l4), aunque la salud repercute en el desarrollo, su vínculo con la seguridad humana no se estableció hasta después de la gripe española y la Primera Guerra Mundial, cuando surgió el concepto de seguridad sanitaria. A pesar de la creación de la OMS en 1948, su trabajo en la erradicación de enfermedades y la resolución sobre seguridad sanitaria global aprobada por esta organización en 2001 , en la que se reconocía el aumento de enfermedades infecciosas producto del crecimiento comercial internacional de alimentos, la urbanización, deforestación y la crisis ambiental, el proyecto de seguridad sanitaria mundial permanece incierto ante las sorpresas y muestra aún debilidades como las reconocidas por la misma OMS ante la pandemia del Ébola en África en 2014 (Lakoff, 20I7).

\section{c. El estado de excepción permanente y el Estado panóptico autoritario:} En la obra clásica de Thomas Hobbes, El Leviatán de I65I, el miedo aparece como un organizador político que permite el tránsito del estado caótico de naturaleza al estado civil. Los momentos de emergencia, en los que el temor a la muerte se hace más patente, aparecen como oportunidades para que el Estado no solo concentre más atribuciones, sino también para que éstas sean legítimas, pues como apunta Savater (2020), la metáfora de la guerra justifica los atropellos a las libertades individuales y la intervención cada vez más intrusiva del gobierno en nuestras vidas para salvarnos del inminente peligro. No resulta extraño que, en una encuesta hecha a finales de abril a ciudadanos de los países de la Unión Europea, $68 \%$ considere que la lucha contra la pandemia justifica las limitaciones a sus libertades individuales y que $51 \%$ esté a favor de que las autoridades usen aplicaciones en sus teléfonos celulares para evitar la propagación del virus (Zalc y Maillard, 2020).

Como señala Agamben (2020), la pandemia nos ha mostrado que el estado de excepción al que los gobiernos nos han acostumbrado desde hace tiempo, se ha vuelto una condición normal. En nombre de la amenaza, hemos aceptado que en la nueva normalidad el distanciamiento social y el confinamiento se conviertan en la regla, que las personas que mueran en este periodo no tengan derecho a un funeral, que la libertad de movimiento sea restringida, que tal como ocurrió en Italia y España, se gobierne con estados de emergencia, que los decretos del poder ejecutivo sustituyan al poder legislativo que, como fue en el caso de Hungría, el primer ministro reciba poderes extraordinarios sin límite temporal ni contrapesos (Paredes, 04 de abril de 2020) o, en un caso más extremo, que se autorice a las fuerzas de seguridad disparar contra quienes violen la cuarenta tal como pasó en Filipinas (El País, 02 de abril de 2020). En la situación de pandemia, algunas de estas medidas pueden parecer comprensibles, sin embargo, la frontera entre las restricciones para evitar la propagación del virus y para 
callar a la prensa y perseguir a los opositores, son delgadas, peor aún, las políticas que se introducen en tiempos de crisis, como apunta Pastor (2020), casi nunca desaparecen una vez superada la emergencia.

La infraestructura para la vigilancia digital, como observa el filósofo sudcoreano Byung-Chul Han (2020), ha resultado ser eficaz para contener la propagación del virus según han demostrado los casos de Taiwán, en los que el gobierno envía simultáneamente mensaje a sus ciudadanos para localizar lugares donde ha habido personas contagiadas y de Corea del Sur donde una aplicación emite alarma cuando las personas se aproximan a un sitio que ha registrado contagios. Sin embargo, países como China han ido más lejos, pues su extensa red de 400 millones de cámaras en las calles y el sistema de crédito social que regula el comportamiento de sus ciudadanos, ha creado, en palabras de Zibechi (2020b), un gigantesco panóptico militar y sanitario que obliga a la población a permanecer encerrada bajo vigilancia constante, un sistema que permite ensayar formas de control ante otras posibles situaciones críticas, como los desastres naturales, pero también las protestas sociales.

d. Desigualdades y movilizaciones sociales: De acuerdo con el Índice de Pobreza Multidimensional de 2019, elaborado por el Programa de las Naciones Unidas para el Desarrollo, que mira más allá del ingreso económico y concibe a la pobreza como un fenómeno de carencias múltiples y simultáneas, tales como la falta de acceso a los servicios de salud, un trabajo digno o la exposición a la violencia, existen I,300 millones de personas que viven en pobreza multidimensional, es decir, casi la cuarta parte de la población de los I0I países estudiados (OPHI-PNUD, 2019).

La concentración de la riqueza en el mundo también se ha vuelto un problema cada vez más preocupante. Según datos del Global Wealth Report (Crédit Suisse, 2019), el 10\% más rico posee $82 \%$ de la riqueza mundial y el I \% más rico acapara por sí solo $45 \%$. El gasto en salud pública en el mundo, apunta Astié-Burgos (20l4), es también desigual, pues mientras en los países ricos es de seis mil dólares por persona, en los pobres es de 20 dólares, en los mismos términos, en los Estados desarrollados existe un médico por cada 400 personas, pero en los de menor desarrollo uno por cada siete mil o hasta treinta y seis mil, como en el África Subsahariana.

Los países más afectados durante la crisis sanitaria han sido aquellos cuyas políticas neoliberales han desmantelado en las últimas décadas el sistema de salud, mediante medidas de austeridad, recortes y privatizaciones (Pastor, 2020). En esa situación, la dependencia hacia industrias privadas se ha hecho mayor en tiempos de crisis, tal como ilustran las declaraciones de Deborah Birx, coordinadora de la respuesta al coronavirus de la Casa Blanca, al señalar que la estrategia estadounidense "está completamente 
enfocada en desencadenar el potencial del sector privado", lo que ocurre después de que Trump disolvió la oficina de respuesta a pandemias del Consejo de Seguridad Nacional en 2018 (Lazzarato, 2020).

Ante tal contexto, como subraya De Sousa (2020), cualquier cuarentena resulta discriminatoria, pues es más difícil para algunos grupos sociales que para otros, en esa lista, subraya el sociólogo portugués, debemos mencionar a las mujeres que sobresalen en profesiones de enfermería o asistencia social y, por lo tanto, están más expuestas al contagio; a los trabajadores precarizados que son más susceptibles a ser despedidos en tiempos de crisis; a los comerciantes ambulantes que no pueden quedarse en casa; a las personas sin hogar, los residentes de las periferias pobres en las grandes ciudades, los refugiados, inmigrantes indocumentados, poblaciones desplazadas internamente, los discapacitados y las personas de la tercera edad.

El virus no discrimina por sí solo a las personas, como agrega Butler (2020), sino que son éstas las que se discriminan entre sí, a causa del nacionalismo, el racismo, la xenofobia y el capitalismo. Así, a pesar de la retórica que tiende a señalar que todos estamos juntos en el mismo barco, apunta Harvey (2020), la COVID- 19 exhibe las características de una pandemia de clase, género y raza, en la que, efectivamente, estamos juntos, pero no en las mismas condiciones. La situación se ha traducido en presiones económicas y sanitarias desproporcionadas sobre los grupos más vulnerables como las minorías racializadas y los inmigrantes, producto de la desigualdad y el racismo institucionalizado. Los afroamericanos y latinos en Estados Unidos reciben salarios más bajos y laboran en condiciones sanitarias más riesgosas, lo que los hace más propensos a resultar contagiados, de esa forma, mientras los afroamericanos representan $6 \%$ de la población del estado de Minnesota, son $29 \%$ de los casos conocidos de COVID- 19 (Healy y Searcey, 02 de junio de 2020); por otra parte, en Nueva York, la tasa de muerte asociada a este virus entre los latinos es 1.6 veces más alta que la registrada por los blancos (Lissardy, 23 de abril de 2020).

El impacto diferenciado de la pandemia entre esos grupos, sumado a la acumulación de rezagos históricos y a la violencia policíaca de la que son víctimas, ha provocado una serie de protestas del movimiento Black Lives Matter, movilizaciones sociales que han alcanzado no solo a varias ciudades de Estados Unidos, sino también de Reino Unido, Francia y Bélgica, por mencionar algunos casos. La emergencia, como señala Pastor (2020), también ha abierto la posibilidad de una nueva ola de revueltas populares que sucedan a las que ya estaban en marcha en todo el mundo antes de la crisis sanitaria, algunas denunciando las desigualdades, otras en contra de las medidas gubernamentales como diversas protestas de la extrema derecha muestran. En cualquier caso, la experiencia del confinamiento nos ha permitido pensar en nuevas formas de protesta, desde el activismo digital 
en las redes sociales, hasta las iniciativas locales que han generado dinámicas de apoyo mutuo y de construcción de comunidad para dar respuestas colectivas desde abajo (Bringel, 2020).

Además de la aceleración de los procesos sociales antes expuestos y de las desigualdades que la pandemia ha acentuado, existen muchos otros fenómenos en marcha, algunos con tendencias muy claras, como la transición a la economía digital, pues las redes sociales y la mensajería móvil se han impuestos como los medios de comunicación dominantes. Las empresas de GAFA (Google, Apple, Facebook y Amazon) y otras como Netflix, Tik Tok y Zoom han resultado ganadoras en las actuales circunstancias, pues como ilustra Ramonet (2020), si antes de la pandemia las acciones de Zoom costaban $\$ 70$ dólares, en marzo de este año valían ya $\$ 160$.

Algunos otros fenómenos, cuya trayectoria futura es aún incierta, son el futuro del populismo de derecha, que no ha ofrecido soluciones efectivas a la crisis, los efectos del "desacople" de las cadenas globales de valor entre el capital estadounidense y el chino, como señalan Actis y Zelicovich (2020), así como el aumento de las nacionalizaciones de firmas estratégicas y la relocalización de ciertas industrias. En el mismo sentido, aún debemos esperar el desarrollo de la vacuna contra la COVID-19 y la política exterior que Estados Unidos desplegará después de las elecciones presidenciales de noviembre de este año.

\section{CONCLUSIONES}

Las consecuencias económicas, políticas y sociales derivadas de la pandemia del COVID- 9 tendrán, como hemos visto anteriormente, un impacto claro en el orden internacional. Considero que veremos cuatro tendencias claras, en primer lugar, y contrario a quienes esperan una realidad radicalmente distinta de la situación previa a la enfermedad, parto de la idea de que, en contraste, veremos la aceleración de procesos que veníamos observando décadas atrás, pero que a raíz de la crisis se han profundizado. El declive de la hegemonía estadounidense, el ascenso del liderazgo chino, la crisis de la democracia y las libertades individuales ante el ascenso de los Estados autoritarios, son tan solo algunos de los procesos que se han manifestado con mayor fuerza en la actual coyuntura, pero que tienen una larga trayectoria que les antecede. En segundo lugar, aún cuando en esta pandemia el menguante protagonismo de Estados Unidos en el orden internacional ha quedado en evidencia, y China ha desempeñado un papel más destacado, la crisis no se ha traducido en el colapso definitivo estadounidense ni en el ascenso incuestionable chino, por lo cual, como esbocé al inicio del texto, estamos ante un escenario más parecido al de la primera posguerra que 
al de la segunda, pues si bien las reglas del sistema han sido puestas en entredicho, las instituciones del orden previo continúan operando y no han dado lugar a nuevas. En tercer lugar, lejos de escenarios utópicos de abierta cooperación internacional o distópicos de tensión permanente, el orden post pandemia, tal como han mostrado las posturas de diversos actores durante la crisis, tenderá a una combinación de estrategias de cooperación, por ejemplo, en materia sanitaria como la información sobre el virus o los desarrollos de una potencial vacuna, y momentos de tensión particularmente entre Estados Unidos y China, pero también incluirá a otros actores como la Unión Europea y Rusia. En cuarto lugar, y finalmente, veremos como producto de las contradicciones inherentes al capitalismo neoliberal, la profundización de las desigualdades asociadas a la pandemia. La creciente geografía de la fragmentación también dará, en consecuencia, mayor espacio a la movilización de los sectores más afectados, al estallido social que hace años observábamos, pero que ahora tendrá que abrirse paso no solo en el contexto de la pandemia, sino también de la crisis económica que le suceda. 


\section{REFERENCIAS BIBLIOGRÁFICAS}

Actis, Esteban y Zelicovich, Julieta (2020). El Ritmo Básico de Reproducción del COVID-19 en la transformación del Sistema Internacional. En Anabella Busso (coordinadora). Relaciones Internacionales en Tiempos de Pandemia. Rosario: Centro de Investigaciones en Política y Economía Internacional, pp. 23-30.

Agamben, Giorgio (2020). ¿En qué punto estamos? La epidemia como política. Buenos Aires: Adriana Hidalgo Editora.

Agnew, John y Corbridge, Stuart (1995). Mastering Space. Hegemony, territory, and international political economy. Londres: Routledge.

Allison, Graham (2017). Destined for War. Can America and China Escape the Thucydides's Trap? Boston: Houghton Mifflin Harcourt.

Astié-Burgos, Walter (2014). Seguridad internacional y diplomacia para la salud global. Revista Mexicana de Política Exterior, (102), pp. 141-171.

Atwood, Kylie (og de mayo de 2020). US blocks UN resolution on global coronavirus ceasefire after China pushes WHO mention. CNN. Dirección URL: https://edition.cnn.com/2020/05/09/politics/us-rejects-un-coronavirus-resolution-china-who/index.html

BBC News (03 de abril de 2020). Coronavirus: US 'wants 3M to end mask export to Canada and Latin America. BBC News. Dirección URL: https:// www.bbc.com/news/world-us-canada-52161032

BBC News (07 de julio de 2020). Estados Unidos se retira de la OMS: Trump notifica oficialmente a Naciones Unidas de la salida del país. BBC News. Dirección URL: https://www.bbc.com/mundo/ noticias-internacional-53329647

Bollyky, Thomas J. (2020). Plagues Tell Us Who We Are. The Real Lessons of the Pandemic Will Be Political. Foreign Affairs. Dirección URL: https:// www.foreignaffairs.com/articles/2020-03-28/plagues-tell-us-who-we-are

Bringel, Breno (2020). Geopolítica de la pandemia, escalas de la crisis y escenario en disputa. Geopolítica(s). Revista de estudios sobre espacio y poder, 11, pp. 173-187.

Butler, Judith (2020). Capitalism Has Its Limits, en Verso. Dirección URL: https://www.versobooks.com/blogs/4603-capitalism-has-its-limits

Chaturvedi, Arpit (2020). A Comparative Analysis of COVID-19 and Black Death of the Mid-14th Century. Envipol. Dirección URL: http://envipol. org/COVID-19-and-black-death.php

Cox, Robert W. (2000). Gramsci, Hegemony, and International Relations. An essay in method, en Andrew Linklater (editor). International Relations. Critical Concepts in Political Science. Nueva York: Routledge. 
Cox, Robert W. (2014). Fuerzas sociales, estados y órdenes mundiales: Más allá de la Teoría de Relaciones Internacionales. En Relaciones Internacionales, 24, pp. 99-116.

Crédit Suisse (2019). Global Wealth Report 2019. Crédit Suisse.

Dagnino, Jorge (2011). ¿Qué fue la plaga de Atenas? Revista Chilena de Infectología, 28(4), pp. 374-380.

De Sousa Santos, Boaventura (2020). La cruel pedagogía del virus. Madrid: Akal.

Drury, Colin (04 de abril de 2020). Coronavirus: Germany and France accuse US of taking face masks as international tensions rise. Independent. Dirección URL: https://www.independent.co.uk/news/world/europe/coronavirusgermany-france-accus-united-states-america-taking-face-masks-ppe-shortage-a9447141.html

DW (16 de marzo de 2020). Alemania se protege de ofensiva de Trump por potencial vacuna de COVID-19. DW. Dirección URL: https://p. dw.com/p/3ZV4O

El País (02 de abril de 2020). Duarte ordena disparar contra quien viole la cuarentena. El País. Dirección URL: https://elpais.com/internacional/2020-04-02/ duterte-ordena-disparar-contra-quien-viole-la-cuarentena.html

Fukuyama, Francis (1989). The End of History? The National Interest, 16, pp. 3-18.

Gómez Muñoz, Janira (22 de julio de 2020). Los claroscuros del presupuesto y fondo pos-COVID aprobados por la Unión Europea. France 24. Dirección URL: https://www.france24.com/ es/20200722-union-europea-fondo-presupuesto-historico-claves

Griffiths, Martin y O'Callaghan, Terry (2002). International Relations: The Key Concepts. Londres: Routledge.

Han, Byung-Chul (2020). La emergencia viral y el mundo de mañana. En Giorgio Agamben, et al. Sopa de Wuhan. Pensamiento Contemporáneo en Tiempo de Pandemias. ASPO, pp. 97-111.

Harrison, Mark (2012). Contagion. How Commerce has Spread Disease. Londres: Yale University Press.

Harvey, David (2020). Política Anticapitalista em Tempos de COVID-19. En Mike Davis, et al. Coronavírus e a luta de classes. Terra sem Amos, pp. 13-23.

Hass, Richard (2020). The Pandemic Will Accelerate History Rather Than Reshape It. Foreign Affairs. Dirección URL: https:// www.foreignaffairs.com/articles/united-states/2020-04-07/ pandemic-will-accelerate-history-rather-reshape-it

Hays, J. N. (2005). Epidemics and Pandemics. Their Impact on Human History. Santa Bárbara: ABC-Clío.

Healy, Jack y Searcy, Dionne (02 de junio de 2020). Pandemia y protestas por la violencia policiaca: dos crisis convulsionan a Estados Unidos. The New 
York Times. Dirección URL: https://www.nytimes.com/es/2020/06/01/ espanol/mundo/george-floyd-protestas-coronavirus.html

Heywood, Andrew (2015). Key Concepts in Politics and International Relations. Nueva York: Palgrave.

Kreibohm, Patricia (2020). Tres pandemias en la Historia. Revista Relaciones Internacionales, 58, pp. 289-294.

La Jornada (27 de mayo de 2020). Lamenta ONU escasa respuesta al llamado a un cese al fuego mundial, en La Jornada. Dirección URL: https://www. jornada.com.mx/ultimas/mundo/2020/05/27/onu-lamenta-oidossordos-a-su-llamado-a-un-cese-al-fuego-mundial-3853.html

Lakoff, Andrew (2017). Unprepared. Global Health in a Time of Emergency. Oakland: University of California Press.

Lazzarato, Maurizio (2020). ¡Es el capitalismo, estúpido!. En Yásnaya Elena Aguilar, et al. Capitalismo y Pandemia. Filosofía Libre, pp. 91-112.

Lissardy, Gerardo (23 de abril de 2020). Coronavirus en Nueva York: el demoledor impacto que tiene la pandemia entre los latinos de la rica metrópoli, en BBC News. Dirección URL: https://www.bbc.com/mundo/ noticias-internacional-52378055

Little, Lester K. (editor). Plague and the End of Antiquity. The Pandemic of 541-750. Nueva York: Cambridge University Press.

Loyer, Barbara y Giblin, Beatrice (2020). ¿Qué mundo geopolítico después de 2020? Geopolítica(s). Revista de estudios sobre espacio y poder, 11, pp. $115-126$.

Martínez Peñas, Leandro (2019). El invierno. Visión jurídico-institucional de las relaciones internacionales en la Edad Media. Valladolid: Omnia Mutantur.

Milani, Carlos (2020). COVID-19 between Global Human Security and Ramping Authoritarian Nationalism. Geopolítica(s). Revista de estudios sobre espacio y poder, 11, pp. 141-151.

Morillas, Pol (2020). CORONAVIRUS: entre lo global y lo local, en CIDOB Opinión, 615.

Noticias ONU (24 de junio de 2020). El llamado del Secretario General al alto al fuego mundial ya cuenta con 170 firmantes, en ONU. Dirección URL: https://news.un.org/es/story/2020/06/1476522

Nye, Joseph S. (1990). The Changing Nature of World Power, Political Science Quaterly, 105(2), pp. 177-192.

OPHI-PNUD (2019). Global Multidimensional Poverty Index 2019. Illuminating Inequalities. United Nations Development Programme and Oxford Poverty and Human Development Initiative.

Pamuk, Şevket (2007). The Black Death and the origins of the 'Great Divergence' across Europe, 1300-1600, en European Review of Economic History, 11(3), pp. 289-317. 
Paredes, Norberto (04 de abril de 2020). Coronavirus en Hungría. 'La primera democracia europea que cae a causa del coronavirus': cómo la crisis del COVID-19 ha puesto en juego el sistema democrático húngaro. En BBC News. Dirección URL: https://www.bbc.com/mundo/ noticias-internacional-52151321

Pastor, Jaime (2020). El (im)posible retorno del Estado al primer plano ante una catástrofe global. Geopolítica(s). Revista de estudios sobre espacio y poder, 11, pp. 165-172.

Pirazzini, Giorgio (2018). La peste que asoló al Imperio de Justiniano, en National Geographic. Dirección URL: https://historia.nationalgeographic.com.es/a/peste-que-asolo-imperio-justiniano_13631/1

Ramonet, Ignacio (2020). La pandemia y el sistema-mundo. Le Monde Diplomatic.

Romero, Juan (2020). La Europa indolente. Una hipótesis sobre los efectos geopolíticos de la pandemia. Geopolítica(s). Revista de estudios sobre espacio y poder, 11, pp. 25-37.

Roy, Arundhati (2020). La pandemia es un portal. En Yásnaya Elena Aguilar, et al. Capitalismo y Pandemia. Filosofía Libre, pp. 51-61.

Savater, Fernando (2020). No estábamos dispuestos a creer lo que veíamos. En Yásnaya Elena Aguilar, et al. Capitalismo y Pandemia. Filosofía Libre, pp. 66-75.

Tunsjø, Øystein (2018). The Return of Bipolarity in World Politics. China, The United States and Geostructural Realism. Nueva York: Columbia University Press.

Watts, Sheldon J. (1999). Epidemics and History: Disease, Power, and Imperialism. New Haven: Yale University Press.

Webb, Michael C. y Krasner, Stephen D. (1989). Hegemonic Stability Theory: An Empirical Assessment, en Review of International Studies, 15(2), pp. 183-198.

Zalazar, Marina (2020). Las dinámicas de la cooperación internacional durante la pandemia. En Anabella Busso (coordinadora). Relaciones Internacionales en Tiempos de Pandemia. Rosario: Centro de Investigaciones en Política y Economía Internacional, pp. 78-83.

Zalc, Julien y Maillard, Robin (2020). Uncertainty/EU/Hope. Public Opinion in times of COVID-19. Bruselas: Public Opinion Monitoring Unit of the European Parliament.

Zibechi, Raúl (2020a). A las puertas de un nuevo orden mundial. En Giorgio Agamben, et al. Sopa de Wuhan. Pensamiento Contemporáneo en Tiempo de Pandemias. ASPO, pp. 113-118.

Zibechi, Raúl (2020b). Coronavírus: A militarizaçao das crises, en Mike Davis, et al. Coronavírus e a luta de classes. Terra sem Amos, pp. 31-33. 